\title{
EFFECT OF URANIUM NITRICUM IN LM POTENCIES ON REDUCTION IN CARDIOVASCULAR RISK AMONG PATIENT WITH TYPE 2 DIABETES MELLITUS
}

\author{
ANWAR AMIR ANSARI, SANJEEV M DOLE*, ANITA PATIL, ARUN JADHAV \\ Department of homeopathic Repertory, Bharati Vidyapeeth Homeopathic Medical College, Bharati Vidyapeeth Deemed University, Pune, \\ Maharashtra, India. Email: sanjeevdole@hotmail.com
}

Received: 27 March 2018, Revised and Accepted: 24 April 2018

\section{ABSTRACT}

Objectives: The present study was carried to determine the reduction in cardiovascular (CV) risk among the patients with type 2 diabetes mellitus (T2DM) after treatment with homeopathic uranium nitricum in LM potencies on the top of unstable background antidiabetic and lipid-modifying therapy.

Methods: This study was open-label, placebo-controlled, parallel arm phase 3 study, stratified according to glycated hemoglobin values $(<7.0$, >7.0). Male and female patients with T2DM ( $>18$ years old) were included in this study from Bharati Vidyapeeth Homeopathic Hospital, Pune. The CV risk was assessed through the United Kingdom Prospective Diabetes Study (UKPDS) search engine. This study was conducted during October 2014December 2015.

Results: Female prevalence was more (52.94\%) than male (47.05\%) in the current study. The average body mass index of the population was 26.98 $(24.9,29.1)$. The significant CV risk reduction $(\mathrm{p}<0.05)$ after treatment with uranium nitricum in LM potencies was observed for non-fatal and fatal coronary heart disease $p<$ among the patients with patients with T2DM.

Conclusion: The homeopathic formulation of uranium nitricum in LM potencies significantly reduces the CV risk when assessed through UKPDS search engine in the patients with T2DM on the background of unstable antidiabetic therapy and LMT.

Keywords: Diabetes mellitus, Type 2, Homeopathy, Cardiovascular risk, United Kingdom Prospective Diabetes Study, Uranium nitricum.

(C) 2018 The Authors. Published by Innovare Academic Sciences Pvt Ltd. This is an open access article under the CC BY license (http://creativecommons. org/licenses/by/4. 0/) DOI: http://dx.doi.org/10.22159/ajpcr.2018.v11i8.26288

\section{INTRODUCTION}

It's now well identified that type 2 diabetes mellitus (T2DM) is related to increased cardiovascular (CV) morbidity and mortality [1-5]. Patients with diabetes have a decrease in life expectancy of around 4-8 years, compared with those without diabetes [6,7]. The community health impact of cardiovascular disease (CVD) in patients with diabetes is already massive and is ever-increasing [8,9]. It has long been known to be a sovereign risk factor for CVD [10]. A personalized approach to CV risk evaluation and management is necessary. Scientifically and carefully chosen homeopathic medicines offer a greater opportunity to reduce the burden of CVD [11,12]. The present investigation was carried to demonstrate the effect homeopathic medicine uranium nitricum in LM potencies in reducing CVD risk in very high-risk patients with diabetes. The United Kingdom Prospective Diabetes Study (UKPDS) was used as an estimation tool for this study $[8,13,14]$.

\section{METHODS}

\section{Study design and endpoint}

The original study was to investigate the effects of uranium nitricum LM potency on blood sugar level. This was the subset of the original study specially objectivised to include high CV risk patients among patients with T2DM. This study was conducted during September 2014-September 2017 at Bharati Vidyapeeth Deemed University Homeopathic Medical College, Pune. Previously patients treated only with uranium nitricum were eligible to enroll in this study. In addition, patients having high blood sugar at baseline with a longer history of DM and willing to check lipid profile voluntarily at baseline and the end of the study. The patients who were unstable on lipid-modifying therapy were excluded from the study.
The study was conducted according to the Declaration of Helsinki $[15,16]$; the protocol was reviewed and approved by the Institutional Review Board/independent ethics committee. All patients provided signed and written informed consent.

The study was open-labeled, randomized, parallel group, and phase 3 study stratified according to glycated hemoglobin (HbA1c) values $(<7.0,>7.0)$. Male and female patients of $>18$ years old were included in this study receiving background unstable antidiabetic and lipidmodifying therapy. The endpoint of this substudy was to evaluate the change in CV risk among patients with diabetes after homeopathic treatment in various LM potencies with the help of UKPDS risk engine. The homeopathic remedy was selected through RADAR 10.0 [17].

\section{Data analysis}

Data were expressed as average (min and max). A 10-year risk with 95\% confidence interval was analyzed using student paired t-test. Analysis of statistical data was performed using Microsoft Office Excel 2010 and GraphPad Prism 6.0 (GraphPad, San Diego, USA). $\mathrm{p}<0.05$ was considered as statistically significant as compared to one another.

\section{RESULTS}

\section{Baseline and demographic characteristics of respondents} All the patients were of South Asian ethnicity with higher female prevalence. Majority of patients were non-smokers and diagnosed with neuropathy. The demographic and baseline characteristics are described in Table 1.

Risk estimates in individuals with T2DM diabetes not known to have heart disease

The overall significant risk reduction after uranium nitricum was observed in non-fatal and fatal coronary heart disease $(\mathrm{p}<0.05)$. In 


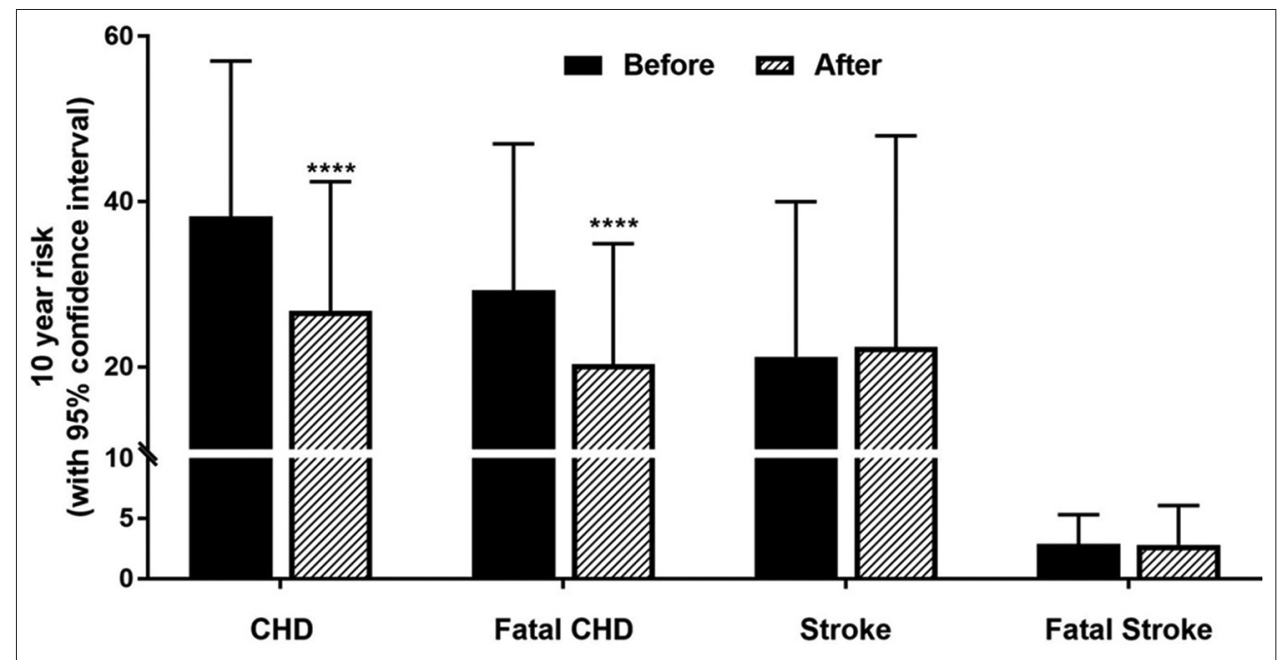

Fig. 1: 10-year risk after uranium nitricum treatment in LM potencies inpatients' with type 2 diabetes mellitus. Data are expressed as a mean \pm standard deviation and analyzed by student pair t-test. ${ }^{* * * *} \mathbf{p}<0.05$ as compared to one another

Table 1: Baseline and demographic characteristics of patients receiving homeopathic treatment in various LM potencies

\begin{tabular}{ll}
\hline Baseline characteristics & \% and average (Min, max) \\
\hline Sex & M: 47.05 \\
Religion & F: 52.94 \\
& H: 64.70 \\
& M: 29.41 \\
Smoking & C: 5.88 \\
& Smokers: 35.29 \\
Complications of diabetes & Non-smokers:64.70 \\
& Neuropathy: 58.82 \\
& Nephropathy: 23.52 \\
Age & Retinopathy: 11.7 \\
BMI & None: 5.88 \\
Duration since diabetes diagnosis & $64.64(50,82)$ \\
Duration since insulin treatment & $26.98(24.9,29.1)$ \\
SBP & $13.29(10,20)$ \\
DBP & $6.47(2,11)$ \\
HbA1c & $130.70(102,150)$ \\
TC & $89.17(68,100)$ \\
HDL & $7.77(7.2,8.6)$ \\
\hline
\end{tabular}

BMI: Body mass index, SBP: Systolic blood pressure, DBP: Diastolic blood pressure, HbA1c: Glycated hemoglobin, TC: Total cholesterol, HDL: High-density lipoproteins

general, no such difference was detected in the risk reduction for stroke and fatal stroke. The details of 10-year risk (with $95 \%$, confidence interval) for coronary heart disease, fatal coronary artery disease, stroke, and fatal stroke are explained in Fig. 1.

\section{DISCUSSION}

The present investigation was designed to evaluate the effects of uranium nitricum on overall risk reduction in fatal and non-fatal coronary heart disease (CHD) and stroke, respectively. It was a subset analysis of original uranium nitricum study on blood sugar level. The patients with high blood sugar at baseline and willing to perform lipid investigations were specifically included in this substudy for further evaluation of CV risk with the help of UKPDS risk engine [8]. The patients were selected only from uranium nitricum treated group; hence, the possibility of high selection bias cannot be ruled out.

The average age and BMI of the population were $64.64(50,82)$ and 26.98 (24.9, 29.1), respectively, with higher female preponderance.
Average blood pressure of the subgroup was systolic blood pressure $130.70(102,150)$ and diastolic blood pressure $89.17(68,100)$. The average $\mathrm{HbA1c}$ was $7.77(7.2,8.6)$, whereas total cholesterol and highdensity lipoproteins-C were $274.05(240,325)$ and $41.47(34,52)$, respectively.

In general, reduction in the 10 -year risk was found significant $(p<0.05)$ among CHD and fatal CHD contrary to fatal and non-fatal stroke. It shows uranium nitricum in LM potencies had significantly reduced the $\mathrm{CV}$ risk as compared to baseline on the top of background LMT and conventional antidiabetic therapy.

\section{CONCLUSION}

Uranium nitricum in LM potencies on the top of background LMT and antidiabetic therapy significantly reduces the CV risk when evaluated through UKPDS risk engine among patients with T2DM.

\section{ACKNOWLEDGMENTS}

Authors acknowledge Hon'ble Manikrao Salunkhe, Vice-chancellor Bharati Vidyapeeth Deemed University for providing necessary infrastructure and facilities for conducting the study.

\section{AUTHOR'S CONTRIBUTION}

Anwar Ansari: Data collection, Sanjeev Dole: Study design, Anita Patil: Drafting of manuscript, Arun Jadhav: Analysis of data. The manuscript was written through contributions of all authors. All authors have approved the final version of the manuscript.

\section{CONFLICTS OF INTEREST}

The authors declare no competing financial interests.

\section{REFERENCES}

1. Adil M, Ghosh P, Venkata SK, Raygude K, Gaba D, Kandhare AD, et al. Effect of anti-diabetic drugs on risk of fracture in type 2 diabetes mellitus patients: A network meta-analytic synthesis of randomized controlled trials of thiazolidinediones. Value Health 2017;20:A526.

2. Kandhare AD, Mukherjee A, Bodhankar SL. Antioxidant for treatment of diabetic nephropathy: A systematic review and meta-analysis. Chem Biol Interact 2017;278:212-21.

3. Tambewagh UU, Kandhare AD, Honmore VS, Kadam PP, Khedkar VM, Bodhankar SL, et al. Anti-inflammatory and antioxidant potential of Guaianolide isolated from Cyathocline purpurea: Role of COX-2 inhibition. Int Immunopharmacol 2017;52:110-8.

4. Visnagri A, Kandhare AD, Chakravarty S, Ghosh P, Bodhankar SL. Hesperidin, a flavanoglycone attenuates experimental diabetic 
neuropathy via modulation of cellular and biochemical marker to improve nerve functions. Pharm Biol 2014;52:814-28.

5. Andayani T, Ibrahim M, Asdie A. The association of diabetes-related factor and quality of life in type 2 diabetes mellitus. Int J Pharm Pharm Sci 2010;2:139-45

6. Sarwar N, Gao P, Seshasai SR, Gobin R, Kaptoge S, Di Angelantonio E, et al. Diabetes mellitus, fasting blood glucose concentration, and risk of vascular disease: A collaborative meta-analysis of 102 prospective studies. Lancet 2010;375:2215-22.

7. Kumar M, Dahiya V, Mishra S, Sharma D, Mishra N, Lahkar M. Cardiovascular disease prevalence and drug utilization patterns at a tertiary care hospital in northeastern India. Int J Pharm Pharm Sci 2016;8:116-9.

8. Shivakumar V, Kandhare AD, Rajmane AR, Adil M, Ghosh P, Badgujar LB, et al. Estimation of the long-term cardiovascular events using ukpds risk engine in metabolic syndrome patients. Indian J Pharm Sci 2014;76:174-8.

9. Badole SL, Chaudhari SM, Jangam GB, Kandhare AD, Bodhankar SL. Cardioprotective activity of Pongamia pinnata in streptozotocinnicotinamide induced diabetic rats. Biomed Res Int 2015 $2015 \cdot 403291$.

10. Gu K, Cowie CC, Harris MI. Mortality in adults with and without diabetes in a national cohort of the U.S. population, 1971-1993. Diabetes Care 1998;21:1138-45.

11. To KL, Fok YY, Chong KC, Lee YC, Yiu LS. Individualized homeopathic treatment in addition to conventional treatment in type II diabetic patients in Hong Kong-a retrospective cohort study. Homeopathy 2017;106:79-86.

12. Patil MV, Kandhare AD, Bhise SD. Anti-inflammatory effect of Daucus carota root on experimental colitis in rats. Int $\mathrm{J}$ Pharm Pharm Sci 2012;4:337-43.

13. Ryden L, Grant PJ, Anker SD, Berne C, Cosentino F, Danchin N, et al. ESC Guidelines on diabetes, pre-diabetes, and cardiovascular diseases developed in collaboration with the EASD: The task force on diabetes, pre-diabetes, and cardiovascular diseases of the European Society of Cardiology (ESC) and developed in collaboration with the European Association for the Study of Diabetes (EASD). Eur Heart J 2013;34:3035-87.

14. Ghosh P, Kandhare AD, Raygude KS, Kumar VS, Rajmane AR, Adil M, et al. Determination of the long term diabetes related complications and cardiovascular events using UKPDS risk engine and UKPDS outcomes model in a representative western Indian population. Asian Pac J Trop Dis 2012;2:S642-50.

15. World Medical Association. Code of ethics of the world medical association: Declaration of helsinki. Helsinki, Finland: WMA; June 1964. BMJ 1964;2:177.

16. Rickham PP. Human experimentation. Code of ethics of the World Medical Association. Declaration of Helsinki. Br Med J 1964;2:177.

17. Schroyens F. Synthesis Repertory in Radar 10.0. Assesse, Belgium; 2007. 